\title{
pH Dependence of the Number of Discrete Conformers of Carbonic Anhydrase 2, as Evaluated from Collision Cross-Section Using Ion Mobility Coupled with Electrospray Ionization
}

\author{
Yoshiaki Nabuchi $^{*,+1}$, Kenji Hirose ${ }^{2}$, and Mitsuo Takayama ${ }^{1}$ \\ ${ }^{1}$ Graduate School of Nanobioscience, Yokohama City University, 22-2 Seto, Kanazawa-ku, Yokohama 236-0027, Japan \\ ${ }^{2}$ Biopharmaceutical Market Development, Waters Corporation Asia Pacific Headquarter, \\ 5-14-10 Nishinakanoshima, Yodogawa-ku, Osaka 532-0011, Japan
}

\begin{abstract}
Ion mobility experiments coupled with electrospray ionization (ESI) were conducted to evaluate the folding states of bovine carbonic anhydrase 2 (CA2) under three different $\mathrm{pH}$ conditions. Collision crosssection (CCS) of the CA2 ions generated by ESI revealed the presence of six discrete conformers in the gas phase under the conditions employed in this study. The CCS of the most extended conformer was three times larger than that of the most compact one. The charge state distribution of the CA2 ions was indicative of three conformers being present. Although there was consistency in conformer assignment conducted by CCS and charge state distribution, the CCS measurement was shown to be more effective because the information obtained provided more detailed knowledge of the conformation of the protein.
\end{abstract}

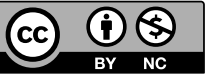

Copyright (c) 2018 Yoshiaki Nabuchi, Kenji Hirose, and Mitsuo Takayama. This is an open access article distributed under the terms of Creative Commons Attribution License, which permits use, distribution, and reproduction in any medium, provided the original work is properly cited and is not used for commercial purposes.

Please cite this article as: Mass Spectrom (Tokyo) 2018; 7(1): A0064

Keywords: IMS, ESI, carbonic anhydrase 2, conformer, CCS

(Received June 29, 2017; Accepted January 10, 2018)

\section{INTRODUCTION}

One of the commonly accepted methods of analyzing protein folding states by mass spectrometry (MS) is to monitor the shift in charge state distribution of multiplyprotonated protein molecules, $[\mathrm{M}+n \mathrm{H}]^{n+}$, generated by electrospray ionization (ESI), ${ }^{1-7)}$ because ESI can directly transfer those ions from the solution to the gas phase. Although the sample solution passes through an electrospray needle with a high electric field, it is thought that analytes remain in solution until the final ionization step. ${ }^{8)}$ If a protein is in a folded conformation, ESI produces gaseous ions with a relatively small charge number, because compactly folded polypeptide chains only allow protonation at the basic side chains that are exposed at the protein surface during the ionization process. In contrast, for an unfolded protein, a significantly large number of protons on the polypeptide chain are accessible, and the ions are shifted to a lower $\mathrm{m} / \mathrm{z}$ region. ${ }^{2-4)}$ A multimodal charge state distribution suggests the coexistence of several conformers. ${ }^{1-5)}$

On the other hand, ion mobility spectrometry (IMS) coupled with ESI is now recognized as a powerful method for analyzing protein conformations in the gas phase, because IMS can separate ions having the same $\mathrm{m} / \mathrm{z}$ values but with different shapes or sizes. The drift time measured for an ion can be converted into a corresponding collision crosssection (CCS), and the CCS provides information related to the conformation of the protein. ${ }^{9-16)}$

We have evaluated the folding states of bovine carbonic anhydrase (CA2) in the gas phase. CA2 is a metalloprotein that catalyzes the reversible hydration of $\mathrm{CO}_{2}$, in other words, $\mathrm{CO}_{2}+\mathrm{H}_{2} \mathrm{O} \leftrightarrow \mathrm{HCO}_{3}^{-}+\mathrm{H}^{+17-19)} \mathrm{CA} 2$ consists of 259 amino acids, in which a $\mathrm{Zn}^{2+}$ ion is bound to the active center by three histidine-imidazoles and $\mathrm{H}_{2} \mathrm{O},{ }^{17)}$ and is involved in various physiological functions, such as respiration, $\mathrm{pH}$ regulation, $\mathrm{CO}_{2}$ and $\mathrm{HCO}_{3}^{-}$transport, and bio mineralization. ${ }^{20,21)}$ We previously reported on the effects of solution $\mathrm{pH}$ on the charge state distribution of CA2 ions produced by ESI and demonstrated that monitoring the $\mathrm{m} / \mathrm{z}$ change caused by the removal of the $\mathrm{Zn}^{2+}$ it was possible to observe the conversion from holo-CA2 to the apo-form. ${ }^{22)}$ From the product ion spectra obtained under several different solvent conditions, we showed that the folding states of the C-terminal region of the protein were influenced by the solvent. ${ }^{23,24)}$ However, the relationship between the folding states of CA2 ions and their molecular size have not yet been examined.

In the present study, we used a mass spectrometer

*Correspondence to: Yoshiaki Nabuchi, Chugai Pharmaceutical Co., Ltd., 1-135 Komakado, Gotemba, Shizuoka 412-8513, Japan, e-mail: nabuchiysa@chugai-pharm.co.jp

' Present address: Chugai Pharmaceutical Co., Ltd., 1-135 Komakado, Gotemba, Shizuoka 412-8513, Japan 
equipped with a traveling wave ion mobility system to measure the mobility of multiply-charged CA2 molecules generated by ESI at three different $\mathrm{pH}$ conditions. The $\mathrm{pH}$ dependence of the number of conformers and the CCS values observed for each charge state was evaluated, and the folding states of the CA2 ions were elucidated from the CCS obtained at different $\mathrm{pH}$ conditions. The results were compared to the folding states evaluated from the charge state distribution.

\section{EXPERIMENTAL}

\section{Materials}

CA2 from bovine erythrocytes was purchased from Sigma (St. Louis, MO). Equine myoglobin and equine cytochrome $c$, which were used as calibrants for CCS measurements, were obtained from Sigma. All other reagents, such as acetic acid, ammonium acetate, and methanol were of the highest grade available and obtained from Wako Pure Chemical Industries, Ltd. (Osaka, Japan). Purified water was prepared by Milli-Q Advantage A10 (Merck Millipore, Billerica, MA).

\section{Sample preparation}

An approximately $100 \mathrm{pmol} / \mu \mathrm{L}$ solution of CA2 was prepared by dissolving the protein in purified water. To dilute the CA2 solution for MS, the following solvents were prepared: (1) $0.1 \%$ formic acid (pH 2.6), (2) $0.3 \%$ acetic acid ( $\mathrm{pH} 3.8$ ), and (3) $20 \mathrm{mM}$ ammonium acetate solution $(\mathrm{pH}$ 6.5). The $\mathrm{pH}$ of these solutions was adjusted with aqueous ammonia. The analyte CA2 concentration prepared to acquire ESI mass spectra was approximately $10 \mathrm{pmol} / \mu \mathrm{L}$. The CA2 solutions were maintained at ambient temperature for at least $15 \mathrm{~min}$ to complete the conformational shift and the
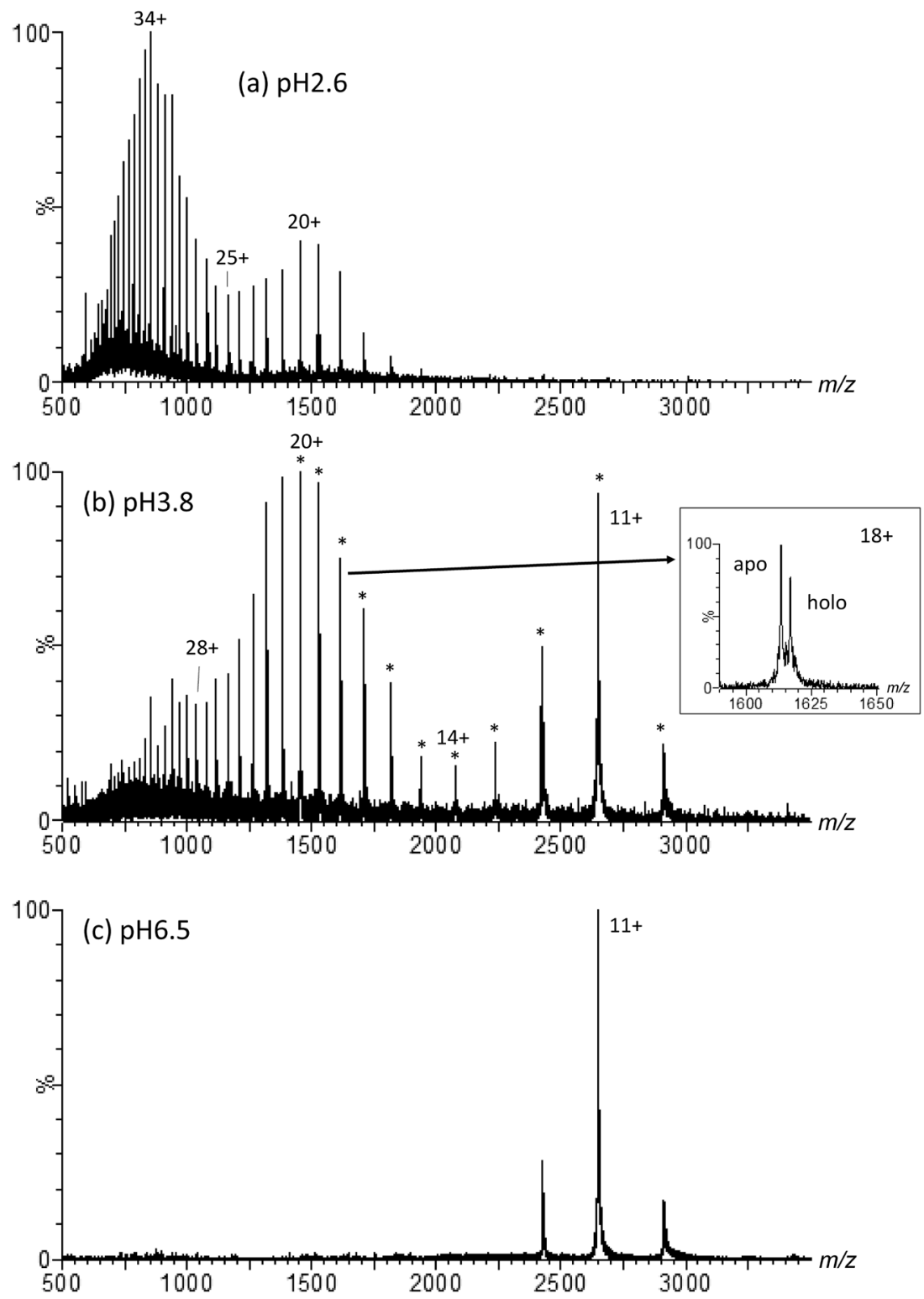

Fig. 1. ESI mass spectra of $\mathrm{CA} 2$ measured at three different $\mathrm{pH}$ conditions.

A CA2 concentration of approximately $10 \mathrm{pmol} / \mu \mathrm{L}$ was used for the measurements. CA2 was dissolved in (a) $0.1 \%$ formic acid (pH 2.6), (b) $0.3 \%$ acetic acid, adjusted to $\mathrm{pH} 3.8$, (c) $20 \mathrm{mM}$ ammonium acetate ( $\mathrm{pH} 6.5$ ). Bi- and tri-modal charge state distributions were observed at $\mathrm{pH} 2.6$ and 3.8, respectively. The holo-CA2 ions were dominantly observed in $\mathrm{pH}$ 6.5. Asterisks indicate ions that are both holo- and apo$\mathrm{CA} 2$. Three ensembles A-C were assigned from the charge state distribution. 


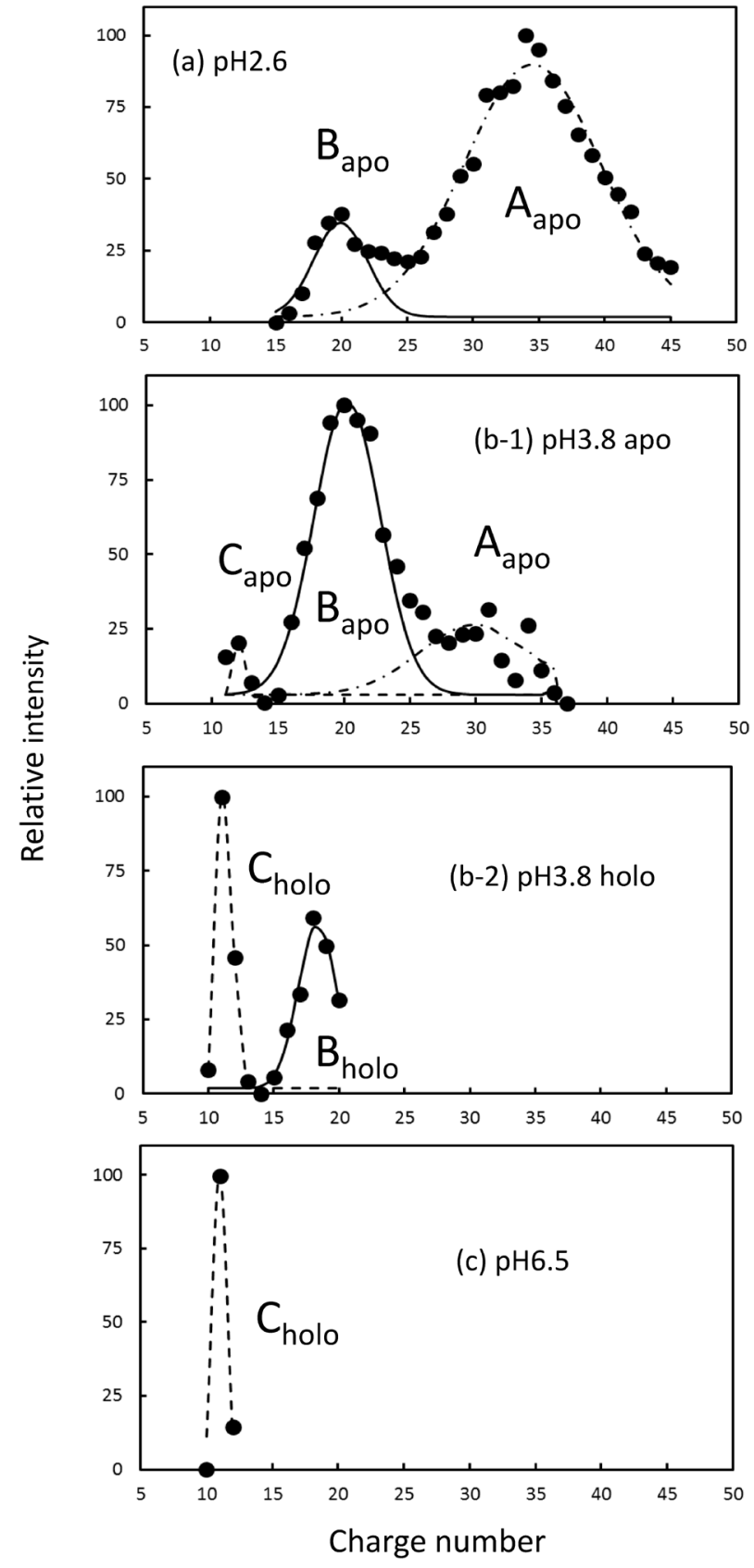

Fig. 2. The results of deconvolution of charge state distribution of CA2 ions in ESI mass spectra obtained at three different $\mathrm{pH}$ conditions.

The raw data are shown in Fig. 1. Presence of three components was indicated.

samples were then infused into a mass spectrometer.

\section{Mass spectrometry}

Mass spectra were obtained with a SYNAPT G2-Si HDMS quadrupole IMS orthogonal acceleration time-offlight mass spectrometer equipped with an electrospray ion source and a MassLynx data processor (Waters Corp., Milford, MA). The mass spectrometer was set to detect positive ions. The following data acquisition parameters were employed: electrocapillary voltage of $3.0 \mathrm{kV}$, sample cone voltage of $30 \mathrm{~V}$, source temperature of $100^{\circ} \mathrm{C}$, and desolvation temperature of $200^{\circ} \mathrm{C}$. To measure ion mobility, nitrogen was used as a buffer gas, and IMS cell pressure was maintained at $3.1 \mathrm{mbar}$. The IMS wave velocity was $500 \mathrm{~m} / \mathrm{s}$ and the wave pulse height was $35 \mathrm{~V}$. The flow rate at which sample solutions were directly infused was $5.0 \mu \mathrm{L} / \mathrm{min}$.

The obtained drift times were converted into CCS values using the procedure outlined by Robinson et al. ${ }^{9,25)}$ Equine myoglobin and equine cytochrome $c$, each of which were dissolved in $49 \%$ (v/v) methanol containing $2 \%(\mathrm{v} / \mathrm{v})$ acetic acid, were used as calibrants and the calibration data were obtained using the same IMS parameters as those for CA2. Myoglobin ions of $15+$ to 24+ and cytochrome $c$ ions of $13+$ to $19+$ were used for the calibration plot. The entire range of CCS was obtained from the formula derived from the calibration plot. The CCS for CA2 was calculated from the published X-ray structure ${ }^{17)}$ (RCSB PDB: 1V9E) using the MOBCAL software. ${ }^{26,27)}$

To estimate the number of independent conformers in ESI mass spectra, chemometric processing was conducted using the Origin 8.5 software (Origin Corp., Northampton, MA) as described previously. ${ }^{28)}$

\section{RESULTS AND DISCUSSION}

\section{ESI mass spectra of CA2 at widely varying $\mathrm{pH}$ conditions}

ESI mass spectra of CA2 obtained at three different $\mathrm{pH}$ conditions are shown in Fig. 1. At $\mathrm{pH} 2.6$, two local maxima at $20+(\mathrm{m} / z$ 1452.2) and $34+(\mathrm{m} / z$ 854.6) and a local minimum at $25+(\mathrm{m} / \mathrm{z} 1162.0)$ were observed in a bimodal charge state distribution of $[\mathrm{M}+n \mathrm{H}]^{n+}$ corresponding to apo-CA2 (Fig. 1a). In the spectrum obtained at $\mathrm{pH} 3.8$, ions corresponding to both apo-CA2 and holo-CA2 were detected. The multiply-charged holo-ions, $[\mathrm{M}+n \mathrm{H}+\mathrm{Zn}]^{n+}$, were observed from $10+$ to $20+$ and the apo-ions $[\mathrm{M}+n \mathrm{H}]^{n+}$ were observed at all the charge numbers except $10+$. In the spectrum, a trimodal charge state distribution was observed with local minima at $14+(\mathrm{m} / \mathrm{z} 2074.0$ for the apo-ion and $\mathrm{m} / \mathrm{z} 2078.6$ for the holo-ion) and $28+(\mathrm{m} / \mathrm{z} 1037.5$ for the apo-ion), as shown in Fig. 1b. The distributions of the apoand holo-ions were not correlated with the trimodal charge state distribution. At $\mathrm{pH}$ 6.5, holo-CA2 ions from $10+$ to $12+$ were observed with the maximum at $11+(\mathrm{m} / z$ 2645.2, Fig. 1c).

We also conducted a chemometric analysis to determine the number of independent conformers in the multimodal charge state distribution of ESI mass spectra (Fig. 1). The results obtained suggested that CA2 ions were composed of three components for the apo-ions (A-C) and two components for the holo-ions (B and $\mathrm{C}$ ) under the conditions used in this study (Fig. 2). This indicates that apo- and holo-CA2 consist of three and two conformers, respectively. The enzymatic activity of CA2 is known to be proportional to the binding rate of $\mathrm{Zn}^{2+}$, and the enzyme has both hydration and dehydration activities at $\mathrm{pH} 6.5{ }^{29)}$ The CA2 ions observed at $\mathrm{pH} 6.5$ were holo-CA2 ions and belonged to component $\mathrm{C}$. Therefore, component $\mathrm{C}$ reflects the folded conformation of $\mathrm{CA} 2$, while the ions comprising component $\mathrm{A}$ are all in the apo-form. Indicating that the component likely consists of inactive extended conformers. On the other hand, component $\mathrm{B}$ was observed at $\mathrm{pH} 2.6$ and $\mathrm{pH}$ 3.8 but not at $\mathrm{pH} 6.5$, indicating that ions belonging to this component do not represent physiologically active conformers. At pH 3.8, component B contains some holo-CA2 ions 
(a) $\mathrm{pH} 2.6$

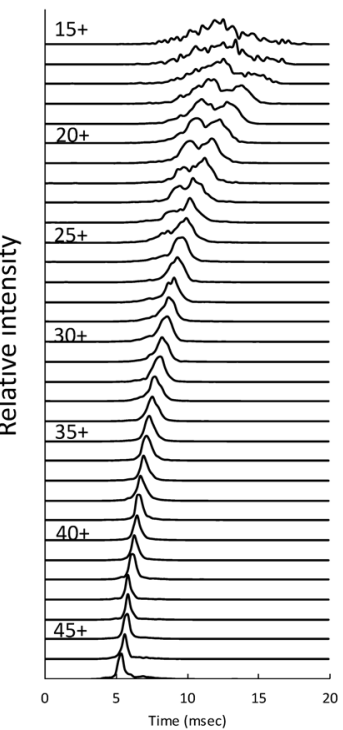

(b-1) pH3.8 apo

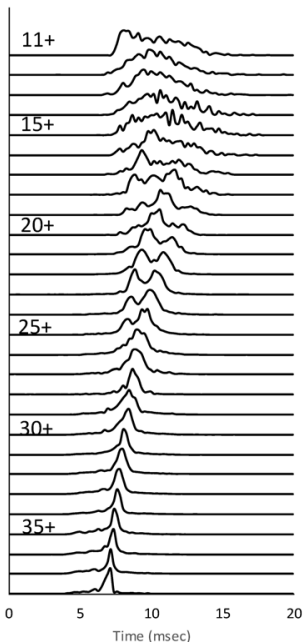

(b-2) pH3.8 holo

(c) $\mathrm{pH} 6.5$

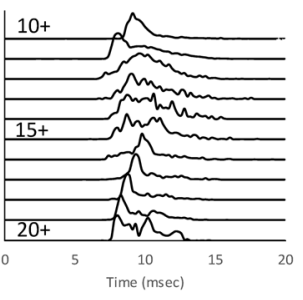

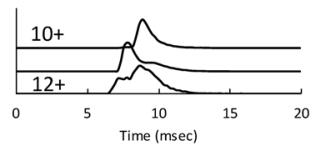

Fig. 3. Driftgrams of multiply-charged CA2 ions (a) at pH 2.6, (b-1) apo-ions at pH 3.8, (b-2) holo-ions at pH 3.8, and (c) at pH 6.5.

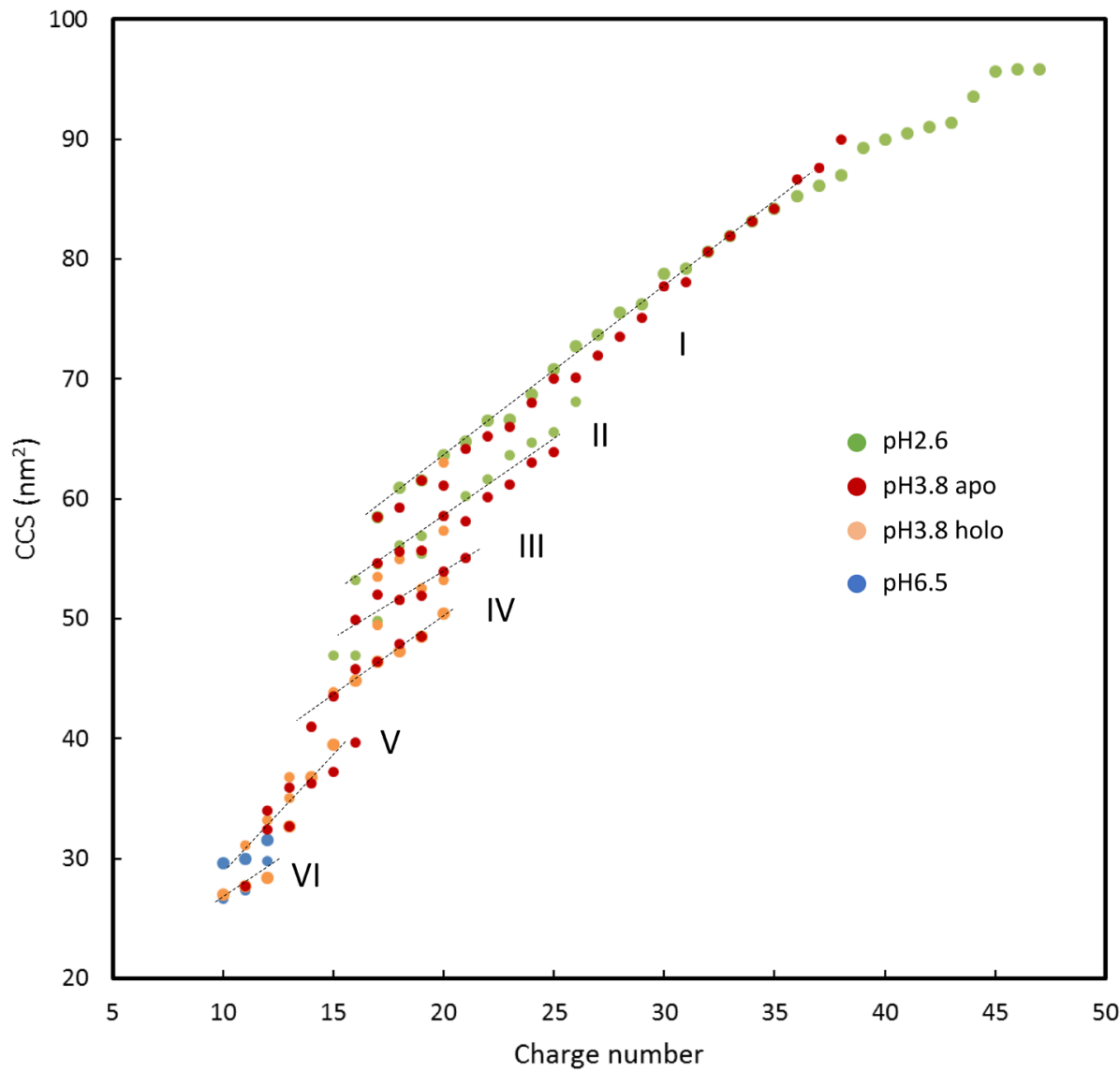

Fig. 4. Plot of charge number vs. peak top CCS of driftgrams obtained under the three pH conditions shown in Fig. 3

The plots were revealed to be divided into six conformers (I-VI).

with lower charge numbers. It can be concluded that component $\mathrm{B}$ consists of apo- and holo-ions, suggesting that the component might be in a transition state to component $\mathrm{A}$ which is dominantly observed at $\mathrm{pH}$ 2.6.
$\mathrm{pH}$ dependence of the number of discrete conformers observed in IMS experiments

Ion mobility experiments were performed to obtain information concerning the gas-phase conformation of the 


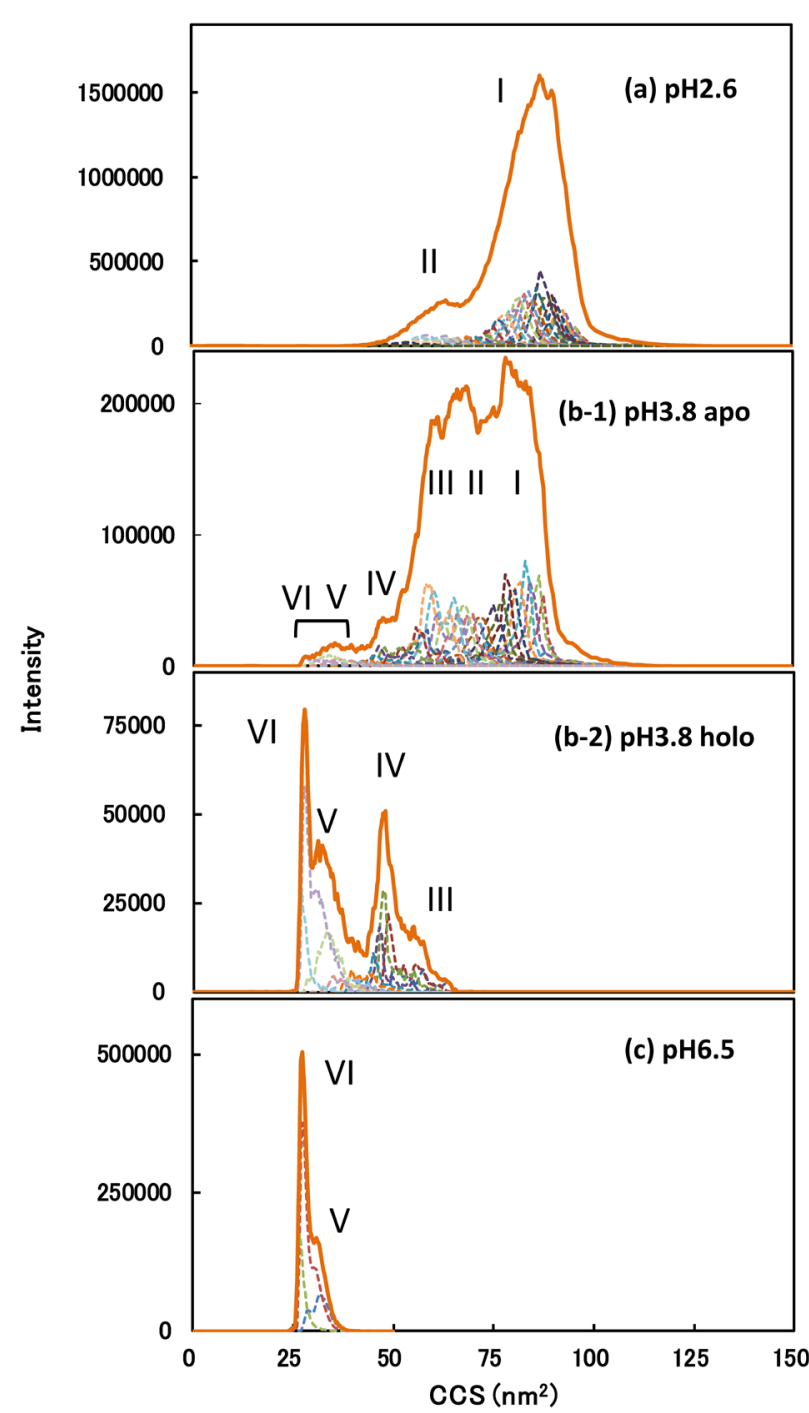

Fig. 5. CCS distribution of CA2 ions produced under three different $\mathrm{pH}$ conditions.

The dashed lines show the CCS distribution of each multiplycharged ion obtained under the specified condition. The bold line shows the sum total of the dashed lines. The measurements were conducted at $\mathrm{pH}$ (a) 2.6, (b) 3.8, and (c) 6.5 . The maximal CCS became larger with decreasing $\mathrm{pH}$ of the sample solution. Roman numerals indicate the corresponding conformers shown in Fig. 4.

CA2 ions at $\mathrm{pH} 2.6,3.8$, and 6.5. The driftgrams obtained are shown in Fig. 3. The singlet peak observed in higher charge numbers $29+$ to $47+$ at $\mathrm{pH} 2.6$ suggests that the ions consist of only one conformer. The peak shape became broader as the charge number decreased, and doublet peaks clearly appeared from 25+ (Fig. 3a). At pH 3.8 for apo-ions (Fig. 3b-1), a singlet peak in the higher charge number ions and doublet peaks from $25+$ were observed. The presence of more than two peaks was assumed, since the charge number decreased, suggesting the presence of several conformers. For holo-ions (Fig. 3b-2), the number of the peaks observed in each charge number ion was similar with that of the apo-ions, but the peak shape tended to become narrower than that of apo-ions in the higher charge state. This may be due to a stabilizing effect of $\mathrm{Zn}^{2+}$ on the conformation of the molecule.

At pH 6.5 (Fig. 3c), doublet peaks were obtained at $12+$ charge state, which were shifted to a singlet peak at $10+$. These driftgrams were similar to those of the holo-ion at $\mathrm{pH}$ 3.8. Comparing the driftgrams obtained at three different $\mathrm{pH}$ conditions, the drift time and peak shape of ions with the same charge number were relatively similar to each other. This suggests that the charge number of the ions is a factor in determining the size of CA2 ions.

\section{The $\mathrm{pH}$ dependence of the CCS on the conformers observed by IMS}

The peak top CCS of the driftgrams was obtained for the three $\mathrm{pH}$ conditions and the CCS was plotted against the charge number of the ions, as shown in Fig. 4. From the plot, the peak tops could be divided into six groups, indicating the presence of six conformers (I-VI). At pH 2.6, conformers I and II were predominant, while conformers $\mathrm{V}$ and VI were predominant at $\mathrm{pH}$ 6.5. The remaining conformers III and IV were mainly observed at $\mathrm{pH} 3.8$.

The CCS values for the peaks observed on the driftgrams at each charge number were calculated, and the intensity of the ions was plotted against the obtained CCS (dotted line in Fig. 5). The sum total of the intensity of each plot is shown as a solid line in Fig. 5. In the case of the sum total plot at $\mathrm{pH} 2.6$, two conformers I and II corresponding to apo-CA2 were found with CCS values that ranged from 50 to $120 \mathrm{~nm}^{2}$ (Fig. $5 \mathrm{a}$ ), and the top of the peak of conformer I was $87 \mathrm{~nm}^{2}$. Both the range of CCS values and peak widths of these conformers were much wider than the other conformers, indicative of the extended shape of conformers I and II. In the case of $\mathrm{pH} 3.8$ apo-ions, the CCS distribution showed a wide range from 25 to $105 \mathrm{~nm}^{2}$ and more than $50 \mathrm{~nm}^{2}$ ions were abundant. Conformers I, II, and III were contained in this abundant region. In the region less than $50 \mathrm{~nm}^{2}$, three conformers corresponding to IV, $\mathrm{V}$, and VI were considered to be present but conformers $\mathrm{V}$ and VI were not observed for a specific peak (Fig. 5b-1). In the case of $\mathrm{pH} 3.8$ holo-ions, the CCS distribution showed a wide range from 25 to $65 \mathrm{~nm}^{2}$ and the presence of four conformers, III to VI was evident (Fig. 5b-2). A clear valley at $40 \mathrm{~nm}^{2}$ between conformers IV and V was observed. This indicates that these conformers may be separated by an energy barrier. The CCS distribution for conformers $\mathrm{V}$ and VI was similar to that at $\mathrm{pH} 6.5$ (Fig. $5 \mathrm{c}$ ), indicating that the folding states of conformers $\mathrm{V}$ and $\mathrm{VI}$ at $\mathrm{pH} 3.8$ holo are similar to those at $\mathrm{pH}$ 6.5. At $\mathrm{pH} 6.5$ (Fig. 5c), ions corresponding to holo-CA2 were revealed to be composed of two conformers, V and VI. The CCS for these two conformers was between 20 and $40 \mathrm{~nm}^{2}$, and the peak top for conformer VI was approximately $27 \mathrm{~nm}^{2}$. This CCS value is consistent with the value taken from X-ray crystal structure calculated via the MOBCAL trajectory method, indicating $24 \mathrm{~nm}^{2}$. This suggests that the folding state of conformer VI may be similar with that of the crystal structure. Holo-ions observed at pH 3.8 and 6.5 were distributed in a smaller CCS region than that for apo-ions. This suggests that the coordination of $\mathrm{Zn}^{2+}$ may contribute to maintaining the compact shape of the ions.

\section{CONCLUSION}

Ion mobility experiments of multiply-charged CA2 ions generated by ESI at three different $\mathrm{pH}$ conditions indicated 
that the gas phase CA2 ions have six discrete conformers (I-VI) with CCS ranging from 20 to $120 \mathrm{~nm}^{2}$ under the condition employed in this study. The CCS of peak top of the most compact component VI was $27 \mathrm{~nm}^{2}$, whereas that of most extended component I was $87 \mathrm{~nm}^{2}$. The CCS of the most compact conformer was consistent with that of the $\mathrm{X}$-ray crystal structure. The conformation of the CA2 ions was analyzed by evaluating the charge state distribution and the results suggest that three components in the apoions and two components in the holo-ions are present (AC, Fig. 2), whereas mobility measurements showed the presence of six conformers (I-VI). The mobility and CCS values reported here suggest that component $\mathrm{A}$ included conformer I, component B included conformers II, III, and IV, and component $\mathrm{C}$ included conformers $\mathrm{V}$ and VI (Figs. 2 and 5). Although there was consistency between the methods, mobility measurements were shown to be more effective because the information obtained gave more detailed information regarding the conformation of the protein.

\section{REFERENCES}

1) K. De Vriendt, G. Van Driessche, B. Devreese, C. Bebrone, C. Anne, J. M. Frère, M. Galleni, J. Van Beeumen. Monitoring the zinc affinity of the metallo-beta-lactamase CphA by automated nanoESI-MS. J. Am. Soc. Mass Spectrom. 17: 180-188, 2006.

2) D. S. Wagner, R. J. Anderegg. Conformation of cytochrome $c$ studied by deuterium exchange-electrospray ionization mass spectrometry. Anal. Chem. 66: 706-711, 1994.

3) R. Grandori. Detecting equilibrium cytochrome $c$ folding intermediates by electrospray ionisation mass spectrometry: Two partially folded forms populate the molten-globule state. Protein Sci. 11: 453-458, 2002.

4) U. A. Mirza, S. L. Cohen, B. T. Chait. Heat-induced conformational changes in proteins studied by electrospray ionization mass spectrometry. Anal. Chem. 65: 1-6, 1993.

5) A. Dobo, I. A. Kaltashov. Detection of multiple protein conformational ensembles in solution via deconvolution of charge-state distributions in ESI MS. Anal. Chem. 73: 4763-4773, 2001.

6) A. T. Iavarone, J. C. Jurchen, E. R. Williams. Effects of solvent on the maximum charge state and charge state distribution of protein ions produced by electrospray ionization. J. Am. Soc. Mass Spectrom. 11: 976-985, 2000.

7) A. A. Rostom, C. V. Robinson. Disassembly of intact multiprotein complexes in the gas phase. Curr. Opin. Struct. Biol. 9: 135-141, 1999.

8) J. B. Fenn, M. Mann, C. K. Meng, S. F. Wong, C. M. Whitehouse. Electrospray ionization for mass spectrometry of large biomolecules. Science 246: 64-71, 1989.

9) M. F. Bush, Z. Hall, K. Giles, J. Hoyes, C. V. Robinson, B. T. Ruotolo. Collision cross sections of proteins and their complexes: A calibration framework and database for gas-phase structural biology. Anal. Chem. 82: 9557-9565, 2010.

10) D. P. Smith, K. Giles, R. H. Bateman, S. E. Radford, A. E. Ashcroft. Monitoring copopulated conformational states during protein folding events using electrospray ionization-ion mobility spectrometry-mass spectrometry. J. Am. Soc. Mass Spectrom. 18: 2180-2190, 2007.

11) I. Michaelevski, M. Eisenstein, M. Sharon. Gas-phase compaction and unfolding of protein structures. Anal. Chem. 82: 9484-
9491, 2010.

12) X. Zhuang, S. Liu, R. Zhang, F. Song, Z. Liu, S. Liu. Identification of unfolding and dissociation pathways of superoxide dismutase in the gas phase by ion-mobility separation and tandem mass spectrometry. Anal. Chem. 86: 11599-11605, 2014.

13) R. Beveridge, S. Covill, K. J. Pacholarz, J. M. Kalapothakis, C. E. MacPhee, P. E. Barran. A mass-spectrometry-based framework to define the extent of disorder in proteins. Anal. Chem. 86: 10979-10991, 2014.

14) D. Scott, R. Layfield, N. J. Oldham. Ion mobility-mass spectrometry reveals conformational flexibility in the deubiquitinating enzyme USP5. Proteomics 15: 2835-2841, 2015.

15) R. Beveridge, A. S. Phillips, L. Denbigh, H. M. Saleem, C. E. MacPhee, P. E. Barran. Relating gas phase to solution conformations: Lessons from disordered proteins. Proteomics 15: 2872 2883, 2015.

16) Z. Hall, C. V. Robinson. Do charge state signatures guarantee protein conformations? J. Am. Soc. Mass Spectrom. 23: 1161$1168,2012$.

17) R. Saito, T. Sato, A. Ikai, N. Tanaka. Structure of bovine carbonic anhydrase II at $1.95 \AA$ resolution. Acta Crystallogr. D 60: 792-795, 2004.

18) S. Lindskog, J. E. Coleman. The catalytic mechanism of carbonic anhydrase. Proc. Natl. Acad. Sci. U.S.A. 70: 2505-2508, 1973.

19) K. L. Gudiksen, A. R. Urbach, I. Gitlin, J. Yang, J. A. Vazquez, C. E. Costello, G. M. Whitesides. Influence of the $\mathrm{Zn}$ (II) cofactor on the refolding of bovine carbonic anhydrase after denaturation with sodium dodecyl sulfate. Anal. Chem. 76: 7151-7161, 2004.

20) E. M. Papamichael, E. D. Economou, T. C. Vaimakis. Dissolution of the carbonate minerals of phosphate ores: Catalysis by carbonic anhydrase II, from bovine erythrocytes, in acid solutions. J. Colloid Interface Sci. 251: 143-150, 2002.

21) W. S. Sly, P. Y. Hu. Human carbonic anhydrases and carbonic anhydrase deficiencies. Annu. Rev. Biochem. 64: 375-401, 1995.

22) Y. Nabuchi, N. Murao, Y. Asoh, M. Takayama. Probing the unfolding and refolding processes of carbonic anhydrase 2 using electrospray ionization mass spectrometry combined with $\mathrm{pH}$ jump. Anal. Chem. 79: 8342-8349, 2007.

23) Y. Nabuchi, K. Hirose, M. Takayama. The $\mathrm{pH}$ dependence of product ion spectra obtained from precursor ions with the same charge number in ESI of carbonic anhydrase 2. Mass Spectrom. (Tokyo) 2: A0016, 2013.

24) Y. Nabuchi, K. Hirose, M. Takayama. Ion mobility and collisioninduced dissociation analysis of carbonic anhydrase 2. Anal. Chem. 82: 8890-8896, 2010.

25) B. T. Ruotolo, J. L. Benesch, A. M. Sandercock, S. J. Hyung, C. V. Robinson. Ion mobility-mass spectrometry analysis of large protein complexes. Nat. Protoc. 3: 1139-1152, 2008.

26) M. F. Mesleh, J. M. Hunter, A. A. Shvartsburg, G. C. Schatz, M. F. Jarrold. Structural information from ion mobility measurements: Effect of the long-range potential. J. Phys. Chem. 100: 16082-16086, 1996.

27) A. A. Shvartsburg, M. F. Jarrold. An exact hard-spheres scattering model for the mobilities of polyatomic ions. Chem. Phys. Lett. 261: 86-91, 1996.

28) A. Mohimen, A. Dobo, J. K. Hoerner, I. A. Kaltashov. A chemometric approach to detection and characterization of multiple protein conformers in solution using electrospray ionization mass spectrometry. Anal. Chem. 75: 4139-4147, 2003.

29) J. C. Kernohan. The pH-activity curve of bovine carbonic anhydrase and its relationship to the inhibiton of the enzyme by anions. Biochim. Biophys. Acta 96: 304-317, 1965. 